\title{
Constitutional Drift: Spontaneous Co-evolution of Social "Ideas" and Legal "Form"
}

\section{GUNTHER TEUBNER}

Professor emérito da Johann Wolfgang Goethe-university, Frankfurt. E-mail: G.Teubner@jur. uni-frankfurt. de.

SUMMARY: I - Introduction; II - First argument: the double reflexivity of social discourse and legal rules; III - Second argument: hybrid binary meta-coding; IV - Third argument: channels of co-evolution; V - Conclusion.

\section{I-INTRODUCTION}

This volume suggests a drastically different concept of a "constitution" from that with which we are familiar: a constitution, it shows us, should no longer be seen as a monistic normative phenomenon of higher legal rules, but rather as a dualistic normative arrangement, one that connects otherwise epistemically incompatible processes, i.e., the development of constitutional forms and the history of constitutional ideas. This conceptualization destroys the traditional unity of the constitution - be it the political unity of Carl Schmitt or its legal unity à la Hans Kelsen - and dissolves constitutionalism into the tension-ridden duality of two diverse and often contradictory autonomous evolutionary processes.

As described in this volume's introduction, this duality explains the differences between the great historical models of constitutionalism - the American legalist-structural model, the French revolutionary-political model, and the English historicist-social model: each of which represents a different historical configuration of these two interrelated processes. Moreover, it shows how the three constitutional pathologies - juridification, oversocialization, and mutual indifference - emerge out of an imbalance in the interaction between constitutional form and constitutional ideas.

In this chapter, I will explore a third consequence of such a conceptualization: that the conceptual move from constitutional monism 
to constitutional dualism reveals a specific evolutionary dynamics in constitutions - i.e. a "spontaneous" process which produces unforeseen results against the founders' intentions. My thesis is that there is not one uniform evolutionary process through which a constitution reacts to environmental pressures. Rather, constitutions develop via two distinct evolutionary trajectories - one of constitutional form and the other of constitutional ideas. And, moreover, these two trajectories are connected by the dynamics of co-evolution.

My thesis comprises of three arguments. First, I reformulate the interrelation between constitutional ideas and constitutional structures in terms of a double reflexivity of social discourses and legal rules. Second, I show how this double reflexivity occurs under the umbrella of what we can call a "hybrid constitutional meta-code". Third, I demonstrate how a variety of co-evolutionary mechanisms link these two trajectories, and are thereby responsible for a variety of constitutional arrangements. I will develop these three arguments not only in the context of state constitutions, but also in the context of various non-state constitutions, drawing especially on what I will call economic constitutions.

\section{II - FIRST ARGUMENT: THE DOUBLE REFLEXIVITY OF SOCIAL DISCOURSE AND LEGAL RULES}

Even if lawyers do not like to admit it, legal rules do not play the principal role in the workings of a constitution - any constitution, be it a state constitution, an economic constitution, or some other form of social system. Rather, constitutionalization is primarily founded on a self-reflexive set of ideas that give meaning to some autonomous set of social practices, be it politics, the economy, or in some other social sphere. Because of its autonomy, we will refer to this as a "self-constitutionalization". As we shall see, legal structures do play an indispensable role in the process of constitutionalization, but it is more of a supporting role.

A self-constitution, in the first step, is constructed out of the "double

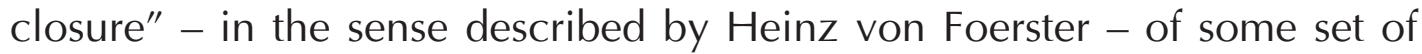
social operations. These operations generate first-order closure by linking a set of self-produced social operations with one another and thereby setting it set apart from its larger environment. This set can then then develop a second-order closure by subjecting these social operations reflexively to a second generate first-order closure by linking a set of self-produced social operations with one another and thereby setting it set apart from its larger environment. This set can then then develop a second-order closure by 
subjecting these social operations reflexively to a second set of operations that tests for validity.

Thus, for example, political constitution acquires its autonomy when it first generates decisionmaking practices involving a closed community of decision-makers, and then generates a double closure by subjecting these practices to a second-order set of autonomous legitimating operations - such as elections, consensus from a diversity of independent power bases (e.g., federalism, separation of powers, or a bureaucratic ordering of diverse specializations), and social and / or judicial understandings of the demands of fundamental rights. The economic constitution acquires its autonomy when, within the money cycle, payment operations are used not only to effect transactions, but also to control the money supply that makes payment operations possible. In the same way, science acquires its autonomy only when it subjects its first-order operations - i.e., empirical observations and formulaic constructs - to second-order operations of epistemology, methodology and theory of science that determine whether or not some particular formulaic observation belongs to the system of science. Such double closure allows a particular social sector to define its external boundaries and thereby establish an internal identity that distinguishes it and its operations from the other social operations that constitute the larger social sphere. It is in this way that these primordial self-constituting processes become autonomous in the strict sense.

Moreover, the status of double-closure requires that relationship between these two sets of operations be "reflexive". This refers to a condition in which radical changes in one of these orders of operations will induce sympathetic evolutions in the other - i.e., radical changes in social operations can induce changes in validity operations, and vice versa.

Without reflexivity, the two sets of operations will de-couple, and lose their coherence as a system.

Along these lines, the epistemic constitutional construct that this volume calls "ideas" - i.e. a medial reflexivity of some association of constitutional practices together with associated cognitive and normative reflections on the identity generated by these practices - represent one kind of doubly-closed system. At the first level, a system of constitutional ideas give meaning to some particular set of constitutional practices; at the second level, it tests for the validity of these meanings by subjecting them to a test for mutual coherence. Im this way, it serves to self-constitute a particular socio-epistemic system. 
By itself, however, it is not sufficient to generate a "constitution" in the strict or technical sense. We should only speak of "constitutions" in the strict sense when a self-constituted socio-epistemic system of "ideas" is supported by another, complementary, self-constitutionalizing process - that of the structural-positive system of law.

More precisely, true constitutionalization occurs when a doubly-closed, self-constitutionalized socio-epistemic system of "ideas" - be it in politics, the economy, or some other sector - becomes structurally coupled with a second kind of doubly-closed, self-constitutionalized system, that of a "legal system" - i.e., what this volume refers to as "form". Like the epistemic social system of ideas, constitutional form is also a reflexive social system, consisting of both primary legal norms that provide first-order closure, and second-order legal norms that provide second-order closure by establishing the validity of these first-order norms. These higher-order legal norms in particular are critical to the constitutionalization process: the application of primary legal norms to a social sphere leads merely to that sphere's juridification (i.e., Kant's Rechtsstaat), not to its constitutionalization. The situation only really becomes constitutionalized when norms of norms - that is, secondary norms - prescribe how the identification, setting, amendment and regulation of competences for the issuing and delegating of primary norms are to occur.

In order to generate a constitutional system, however, the structural coupling of ideas and legal form must itself be reflexive, in the sense that radial changes in the system of ideas cause sympathetic changes in the legal system, and vice versa. As mentioned above, this such reflexivity is necessary to secure the constitution's systemic coherence. But since both ideas and form are themselves reflexive system, this results in a double reflexivity - and it is this double reflexivity that is distinctly characteristic of constitutionalism.

In other words, the precondition for a constitution in the strict sense is that a structural coupling takes place between the reflexive mechanisms of legal structures (that is, secondary legal norm creation in which norms are applied to norms) and the reflexive mechanisms of ideas that give meaning to those legal structures. This occurs when self-constitutionalizing socioepistemic processes that render some particular environment of societal rationalities legal norm creation in which norms are applied to norms) and the reflexive mechanisms of ideas that give meaning to those legal structures. This occurs when self-constitutionalizing socio-epistemic processes that render some particular environment of societal rationalities both meaningful 
and autonomous are themselves juridified by a separate set of self-constitutionalized legal processes. Only in this way can the developmental dynamic typical of constitutions, as described by the introductory chapter, emerge - in the form of an institutionalized co-evolution between these two self-reflexive processes (as we shall explore further in Part IV of this chapter).

It is in this distinctive, double reflexivity of constitutionalism that we encounter its curious duality - a duality that is characteristic of a strict structural coupling and that refutes the widespread presumption that a constitution is a unitary phenomenon. The two extremes of this duality, associated with the names of Hans Kelsen and Carl Schmitt, need to enter into a mutual embrace in both political constitutions and social constitutions. In this sense, a constitution can be reduced neither to a legal structure (á la Kelsen) nor to a socio-political practice (à la Schmitt). It is always a dual phenomenon: a linking of these two innately autonomous processes. From the legal perspective, constitutionalization involves the production of secondary legal norms that are peculiarly interwoven with the fundamental understandings of the social system. From the social perspective, constitutionalization involves the production of secondary epistemic norms that are themselves critically informed by the legal norms recognized by the system. Only when both these conditions operate together does it make sense, in terms of both legal sociology and legal doctrine, to speak of the "elements" of a political constitution, of an economic constitution, of a constitution of the education and science system, or of the digital constitution of the Internet.

What is the reason, though, for this doubling of social reflexivity through the use of secondary legal-constitutional norms? Law comes into the self-constitutionalization processes of social systems when autonomization cannot be fully accomplished using just the first and second order social operations of those social systems. This might occur, for example, when these social operations are unable to stabilize themselves, or when they become indeterminate due to their own internal paradoxes. In such cases, additional closure mechanisms are needed to complete the self-constitution of social autonomy.

The law is one of these additional mechanisms (albeit not the only one). Consider, along these lines, the self-description of the autonomous "state". As noted by Niklas Luhmann, "[t] he political system is only differentiable at all when it describes itself as a state." But the closure of institutionalized politics is not accomplished without formal delineations of what constitutes collectively-binding state power. The reflexive application of first order power dynamics (command) to second order power processes 
(oversight) cannot be exposed to the constant fluctuations of power itself. A higher order to legal norms is needed to bring stability to the reflexive interactions that structure acquiring and exercising power. In this sense, it is only through the structural coupling of politics to law that the political system become autonomous in the form of "the state".

More important still is the contribution made by the law to defusing the paradoxes of political power. As also described in Chapter [Loughlin] to this volume, traditionally the paralyzing paradox of the self-binding nature of "the sovereign" has been normalized - but not resolved - by the establishment of "rule of law". Similarly, the self-constitution of social systems necessarily comes up against its own paradoxes relating to its selfreference - e.g., the paradox of the legitimacy of its own founding - and one way of dealing with this paradox is to externalize "the founding" to the law. This is what happens in state constitutions, but it can also be observed in the self-constitutions other social systems. Thus the autonomy of a social constitution is never autonomy in pure form: it always contains elements of heteronomy. The "self" of the self-constitution must first be defined heteronomously, through legal norms. This is necessary in order to be able to identify itself as an autonomous system.

These additional mechanisms of self-constitution vary quite markedly from one social system to another. Science requires only minimal support from stabilizing legal norms to achieve autonomy. Methodologically, the epistemology of science is itself generally capable of hammering in the boundary stakes that mark out the realm of science on its own, especially since science is not subject to any decision-making imperative. Despite all the worrying about corruption in the academic world, it seems superfluous to attach a binding self-description to science as a collective qua scientific community, or even for the scientific community to be since science is not subject to any decision-making imperative. Despite all the worrying about corruption in the academic world, it seems superfluous to attach a binding self-description to science as a collective qua scientific community, or even for the scientific community to be incorporated into some formal organization in order to secure the scientific credentials of knowledge. Legal systems therefore play a relatively small role in the constitutionalization of scientific activity - although even here, an heteronomous stabilization is still needed in order to provide guarantees of scientific freedom and to secure the persistence of scientific institutions, the latter being then left to their own self-constitutions. 
The economy, by contrast, requires a huge amount of heteronomous stabilization from the law for its self-constitution (albeit still not to the same extent as politics). As is well known, the institutions of property, contract, competition, and currency form the cornerstones of the economic constitution. All of these institutions are constructed out of secondary legal norms that legitimate and validate the practices associated with these institutions. These secondary norms are essential for allowing a double reflexivity to operate within the economic system: a reflexivity in which primarily norms of economic transactions (e.g., exchange) are subject to secondary norms of economic legitimation (e.g., norms of market expectations), that are themselves critically coupled with corresponding primary and secondary norms articulated in the legal system, such as conscionability and good faith, that give needed persistence to these norms of legitimation and expectation. (See also discussion in Part IV.)

\section{III - SECOND ARGUMENT: HYBRID BINARY META-CODING}

To some extent, the argument above recapitulates the argument presented by Martin Loughlin in his chapter XX. But here I want to go further, and show that double reflexivity by itself is not enough. The end point of constitutionalization - be it in politics, in the economy, or in other social spheres - is not achieved until the reflexive relationship between social ideas and legal structures has developed in such a way that a hybrid binary meta-coding emerges. This coding is "binary" in the sense that it recognizes only two possible encoded states - "constitutional/unconstitutional" - in the situations to which it is applied. It is "meta" in the sense that it only operates on decisions that have already been encoded as "legal/illegal" by the self-constituted legal system that is part of the constitutional system.

This produces the distinctive hierarchy that is typical of all constitutions: that is, that of a "constitutional" law - i.e., "the law of laws" - operating above the ordinary law.

But what is really special about this meta-coding is its "hybridity". This constitutional code takes precedence not only over the legal system, but also over the binary codes of the other specialized "function-systems" - such as the economic system, the political system, even the health system when access to health care is a state right - that in toto constitute the constitutional order. As it does with regards to law, this meta-coding exposes the operations of these other function-systems to a higher-level binary reflexivity as to 
whether or not they are or are not behaving in accordance with their larger responsibilities to the constitutional order.

The hybrid nature of this meta-coding can be observed most clearly in the developed political constitutions of the modern nation states. Here, the "constitutional/unconstitutional" distinction is used as a meta-code that applies to two similarly binary-coded subsystems - namely those of law and politics (see, e.g., "juridical constitutions" vs. "political constitutions") - but without causing these subsystems to lose their autonomy from one another. It allows the constitution to be a neutral process of structural coupling: a way of integrating the two social subsystems of politics and law without causing either to lose its autonomy. Similar hybrid meta-codings also crop up - usually implicitly, occasionally explicitly - in the structural couplings of law with other social systems, producing their own constitutional meta-codes.

For example, the constitution of the modern industrial economy has its own kind of hybrid meta-code that provides a seemingly common formula for two quite different types of economic operations. This meta-code assumes hierarchical precedence over both legal and economic binary codings related to the economy, but it actually takes on different meanings depending on whether it is applied to the economic code or the legal code. Applied to the economic code, it subjects exchange procedures to reflexive evaluation in light of their overall social function, and identifies their social and environmental compatibility. Applied to depending on whether it is applied to the economic code or the legal code. Applied to the economic code, it subjects exchange procedures to reflexive evaluation in light of their overall social function, and identifies their social and environmental compatibility. Applied to the legal code, it sits hierarchically over ordinary law, judging legal acts according to whether or not they are in line with the high values and principles set down in the economic constitution.

Thus, while the economic-constitutional meta-code presents itself formally as a simple unitary distinction directrice of "constitutional/ unconstitutional", what we really have before us here is an interesting special case of "essentially contested concepts" - a case where the same term is interpreted in very different ways in different contexts and is implemented in correspondingly different connecting operations. This Janus-faced character of the constitutional meta-code has to do with the fact that by itself, the economic constitution, as itself a structural coupling between two mutually closed social systems (the economic system and the legal system), is unable on its own to attain social-systemic autonomy. Rather than merging 
together into a single system, both the economic and legal systems remain attached to their own independent operational domains - namely, that of market transactions and that of legality respectively. The "constitutional/ unconstitutional" operation provides a common umbrella formula that nevertheless takes on different meanings depending on whether it applies to the economic system, where it expresses market validity, or the legal system, where it expresses legal validity.

The duel nature of the economic-constitutional code necessarily means that, within its domain, legal "structures" and economic "ideas" develop their own programs for that constitution - programs that are normatively independent from each other, but still interrelated (perhaps homeostatically, as Dowdle elsewhere proposes). Each of these programs emerges initially from the reflexive and recursive application of the system's own primary and secondary operations. Yet, their common meta-coding in terms of "constitutional/unconstitutional" causes constant mutual irritation that binds both systems into a co-evolutionary relationship. The fact that in law, the meta-code "constitutional/unconstitutional" is given hierarchical precedence over the legal system's coding of "legal/illegal" not only allows basic principles of the economic system to be injected into the principles of the legal system, but also allows both these sets of principles (legal and economic) to co-evolve in response to evolutions their respective social systems.

This is where we find the real justification for a truly material concept of constitutionalism, as contrasted against the formal and the functional concepts of constitutionalism. Constitutionalized law cannot be reduced simply to compliance with certain decision-making processes (forms), but demands substantive justification by means of content-based constitutional principles (ideas). Such law would not be constitutionally comprehensible without the re-entry of the basic material principles of these two self-constituted social system into the constitution's legal system. In the context of the economic constitution, for example, this binding of constitutional law to specific economic ideas is certainly not prescribed by natural law. Rather, it is the result of historically changing processes of reflexivity in which the social self-constitution of the economic system is constantly being reconstructed in law as an ensemble of content-based, constitutional-legal norms. Something comparable also occurs in the opposite direction. Constitutional meta-coding causes the law to become reconstructed in economic terms, such as the law of contract being reconstructed as a particular operationalization of economic transactions; property as a particular operationalization of 
social relationships; competition law as a particular operationalization of economic efficiency; and company law as a particular operationalization of collective economic "rationality".

The reciprocal re-entry of the material principles of economy and law into the economic constitution thus gives rise to two different "imaginary spaces" within that constitution: two different constitutional programs one aimed at the economy, the other aimed at the law. These programs are directed, jointly but separately, by their shared constitutional meta-code. The resulting dualization of that meta-code's meaning becomes especially clear in relation to one of the classic programs of the economic constitution, namely property. In economic terms, property describes the "disjunction of the requirement for consensus" that governs socio-economic coordination. In legal terms, property refers to an exclusive subjective right. The economic constitution uses both concepts according to context. It thereby takes the form of a language game in which there is a peculiar double structure to its common distinction directrice of "constitutional/unconstitutional". But as a exclusive subjective right. The economic constitution uses both concepts according to context. It thereby takes the form of a language game in which there is a peculiar double structure to its common distinction directrice of "constitutional/unconstitutional". But as a language game, it does not develop the strength to become an autonomous, self-reflexive "language" in its own right. Rather, it forms a peculiar "binding institution" in which the law and the economy are closely coupled, and thereby mutually irritate one another. In doing so, it produces a bilingualism in that it continually translates law into economics and vice versa.

\section{IV - THIRD ARGUMENT: CHANNELS OF CO-EVOLUTION}

Constitutional history shows itself to be co-evolutionary. Under the umbrella of their "constitutional/unconstitutional" meta-coding, political constitutions "develop" via a co- evolutionary process that links the development of their political programs (i.e., their self- constitutionalizing systems of constitutional ideas) and the development of their legal programs (i.e., self-constitutionalizing systems legal forms and structures). Societal constitutions co-evolve by linking their social programs with their legal programs. And both the political and the social constitutions co-evolve due to the hybrid capacities of this constitutional meta-coding.

Contrary to a unified social evolution in which constitutional evolution comes about simply from external environmental pressure operating 
on various social systems, each self- constitutionalizing system with the constitutional system has own very specific and very distinct evolutionary mechanisms. Each system - legal, economic, social - displays different patterns of variation, selection, and retention. Their autonomous evolutionary processes influence each other via mechanisms of co-evolution. This is the opposite of the usual assumption in constitutional history of a unified evolutional trajectory that is driven purely by forces of economic, moral, or political natural selection. Rather, it involves diverging evolutionary trajectories taking place simultaneously within a single constitutional system. To use the terminology of the first chapter to this volume, the "structure" of constitutional law at the one side and the "ideas" of the focal social sector (e.g., economy, politics, science, education) on the other all operate according to their own idiosyncratic and independent evolutionary mechanisms, while the coevolutionary process of the constitution system as a whole coordinates these evolutionary dynamics so as maintain sectorial autonomy and identity.

If one wishes to understand the particularities of any single constitution, one must therefore look not merely at the individual evolutionary paths of its respective sectoral social systems, but also more specifically at how their mutual channels of reciprocal influence have developed within and through this process of co-evolution.

Consider, for example, the two different kinds of economic constitutions identified by the varieties of capitalism literature, those of liberal market economies and those of coordinated market economies. Economic constitutions have always been shaped by specific legal, political, scientific, and educational developments in their region. This is the first source of their differences: they display cultural particularities that can only be explained by reference to the special histories of their various constituent, self-constitutionalized sub- systems. The other source of their differences, that which interests us now, is to be found in the specific co-evolutionary interactions between their legal and the economic subsystems.

These interactions can be arranged along to two dimensions. One dimension concerns the quality of the co-evolutionary influences, the other concerns the density of their co- evolutionary co-ordination.

As regards the quality of their co-evolutionary influence, the interactions between constitution's subordinate social systems can involve:

- Irritation: in which external stimuli originating from one social system excite internal evolutionary selection processes in the 
other system, but do not direct these processes to any particular procedural or substantive ends;

- Simulation: in which external stimuli originating from one subordinate social system cause the selections mechanisms of the other social system to reproduce (via mimesis) the selection mechanism of the stimulating system, without necessarily reproducing the selection results of the stimulating system; and / or

- (via mimesis) the selection mechanism of the stimulating system, without necessarily reproducing the selection results of the stimulating system; and / or

- $\quad$ Endogenous symbiosis: in which external stimuli originating in one social system cause the other system to incorporate into its own stabilization mechanisms the results of the stimulating system's selection processes.

As regards the density of co-evolutionary coordination, co-evolutionary interactions can be classified as follows:

- $\quad$ spontaneous vs. organized: the degree to which the interactions are the product of or subject to human intentionality;

- $\quad$ simultaneous vs. sequential: whether the mutually co-evolutionary dynamics occur at the same time;

- $\quad$ fragmented vs. integrated: the degree to which the evolutionary changes are systemtically harmonized;

- $\quad$ antagonistic vs. coordinated: whether the co-evolution takes the form of positive or negative feedback loops.

Drawing from the comparative experience of judicial review of standard form contracts in the United States and Germany, I will sketch how the different economic constitutions of these two countries - the liberal market economy of the United States vs. the coordinated market economy of Germany - are products of different co-evolutionary channels.

In private law, judicial review of standard contracts in the economic constitutions is the functional equivalent of constitutional review of political legislation in state constitutions.

Standard contracts are not voluntary agreements by two contracting parties, but rather market-regulatory mechanisms that are unilaterally 
imposed on the market by private economic organizations. When courts review standard contracts under the somewhat old- fashioned private-law principles of good faith (as is the case in Germany) or unconscionability (as in the United States), they are engaged in the same general activity as are constitutional courts when reviewing legislative acts according to constitutional principles.

Traditional comparative law sees judicial review of standard contracts in these two countries in terms of similarities, convergences, and/or possibilities for legal harmonization. Traditional economics sees it in terms of pressures of natural selection driven by competitive dynamics of economic efficiency. The approach developed here, by contrast, identifies the drastic differences in the legal rules of these two regimes, as well as differences in their respective institutional advantages and disadvantages, and traces these differences back to the different mechanisms of constitutional co-evolution particular to their respective constitutional systems.

From a traditional perspective, the two regimes' treatment of standard contracts seems highly convergent. The formal similarities of what we might call "economic constitutional review" in the two countries are indeed astounding. Standard contracts are subject in both the USA and in Germany to judicial review via very similar sets of economic-constitutional concepts, policies, and principles. Both regimes have recognized standard contracts as being legally enforceable despite their somewhat asymmetric character. Both make the validity of these contracts dependent on certain conditions (good faith, fairness, unconscionability) that clearly differentiate them from ordinary contracts.

Similarities between these two regimes can also be found with regards to the quality of their respective co-evolutionary influences. Both regimes favor leaving the development of the new forms of contracts to the whims of coincidental irritations: economic innovations in standard-form contractual practices irritate the legal system via introducing new kinds of cases into the court system that produce new, idiosyncratic forms of legal evaluation; while new legal doctrines affect changes in the forms of the standardized contracts. At the same time, however, both systems also evince parallel manifestations of both simulation and standard-form contractual practices irritate the legal system via introducing new kinds of cases into the court system that produce new, idiosyncratic forms of legal evaluation; while new legal doctrines affect changes in the forms of the standardized contracts. At the same time, however, both systems also evince parallel manifestations of both simulation and endogenous symbiosis. In both countries, the principles 
of judicial review internally reproduce selection criteria used in economic evaluations of these kinds of contracts (simulation). Both also occasionally assimilate the results of economic evaluations establishing the validity of standard contracts into their own findings of legal validity, even without reproducing the selection processes internally (endogenous symbiosis).

But divergences become apparent when one begins to scrutinize the different weights that each constitutional regime gives to processes of simulation vs. processes of endogenous symbiosis. In The United States, legal-economic co-evolution place primarily through endogenous symbiosis. In German practice, it is driven much more by simulation.

This is because in the United States, standard-contracts forms are developed independently by individual firms. This decentralized mode of private governance leads to a plethora of standard-contract types. So great is this individuated diversity that it transcends the informational capacity of the reviewing courts. Courts are therefore forced to defer to the evaluative results produced by the economic system, and autonomous judicial control of standard contracts is relatively underdeveloped.

In Germany, by contrast, it is not the individual firm, but sectorial business associations that formulate standard contract regimes. Thus, in principle, each industrial sector has a standardized standard-contract form that is used by all the firms in that sector. This results in much reduced variation in standard-contract forms. Moreover, these contractual regimes are frequently scrutinized by public authorities - in particular the Federal Cartel Office, or Bundeskartellamt. As a result, German courts have a relatively good overview of the standard-contract characteristics in each sector. In contrast to the US, this allows for autonomous and highly detailed judicial review of standard contract regimes, in which German courts incorporate into their own selection mechanisms autonomous legal principles that reproduce the manner in which the economic subsystem pertinent to the relevant industrial sector distributes risks and imparts transparency. The distinct political and legal factors that underlie their particular formulations in turn frees the courts from having to symbiotically defer to the outcomes of economic selection processes that themselves remain external to the legal system.

And divergence between these two regimes becomes even more apparent when we consider the respective densities of their co-evolutionary contacts. In the United States, as we saw, individual firms implement their own contractual regimes, often with the other side of the transaction 
replying with its own firm-specific standard contract, and it is market competition that decides which one prevails. It is, in this sense, spontaneous. American courts, which as has already been noted exercise relatively weak constitutional control over standard contracts, also react post hoc when unacceptable risks have materialized. In this way, the American regime also manifests itself sequentially. It is also highly fragmented: in deciding issues raised by standard contracts, courts do so not by applying uniform standards of contract law, but by examining for highly context-specific incidents of tort-like misconduct rather than for more generalizable problems of the distribution of risks inherent in the standard contract form itself, as per contract law. Such fragmentation is further catalyzed by the intervention of numerous autonomous state and federal agencies and autonomous state and national legislative frameworks.

In sum, in the United States, the density of co-evolutionary coordination between the legal and the economic subsystems of the economic constitution insofar as standard contracts are concerned is spontaneous, fragmented, and sequential. There is a plethora of standard-contractual regimes, and judicial intervention on constitutional grounds is markedly limited. This is in direct contrast to the density of co-evolutionary coordination in Germany, which is organized (rather than spontaneous) and integrated (rather than fragmented). It is integrated (rather than fragmented) in the sense that - as we have seen - standard contracts are formulated by sectorial business associations rather than by individual firms. It is organized in that the formulation of such contracts is specifically designed (especially by the Bundeskartellamt) to strike a balance between a variety of social concerns - not simply those of a particular firm or industrial sector. These include, for example those of the class of actors that are most likely to be on the other side of that standard contract; those of classes of likely-affected third parties (especially as concerns distribution of liability for risk and Bundeskartellamt) to strike a balance between a variety of social concerns - not simply those of a particular firm or industrial sector. These include, for example those of the class of actors that are most likely to be on the other side of that standard contract; those of classes of likely-affected third parties (especially as concerns distribution of liability for risk and insurance); and those of various political, administrative, and supervisory bodies (and in particular the Bundeskartellamt itself).

Consequently, in contrast to American courts, German courts do heavily intervene in the construction of the standard contract regulatory regime. This is incomprehensible from an economic standpoint, which 
regards such heavy intervention as just another case of "Eurosclerosis". From that standpoint, such intervention seems inefficient and paternalistic. It is paternalistic in that it not only imposes protections on consumers without their consent, it also second-guesses professional market judgment regarding the correct assignment of risk. It is inefficient in that it discourages the development of new and more efficient contract formulations.

But such heavy judicial intervention nevertheless does make sense from a constitutional standpoint, and in particular from the constitutional perspective which derives from Germany's specific variety of capitalism its coordinated market economy as distinguished from the American liberal market economy. From that perspective, the criterion for judicial intervention is whether or not the contractual form under review represents an authentic innovation - i.e., an innovation that increases the productivity of the industry - or simply a spurious innovation - i.e. an innovation that simply transfers exposure to risk to the other party without promoting productivity. The policy principle for such review is not just to protect medium-sized companies, but to promote productivity enhancing co-operation between firms by protecting the autonomy of and facilitating co-operation among all the stakeholders affected by the contractual transaction.

\section{V- CONCLUSION}

In this chapter the interrelation between constitutional structures and constitutional ideas has been reformulated in terms of a double reflexivity of social discourses and legal rules. Double reflexivity means the precondition for a constitution is that a structural coupling takes place between the reflexive mechanisms of legal structures (that is, secondary legal norm creation in which norms are applied to norms) and the reflexivity of ideas in the social sector related to it. This applies to political constitutions as well as to various non-state constitutions, especially to economic constitutions. This interrelation occurs under the umbrella of a "hybrid constitutional meta-code". It has been demonstrated how a variety of co- evolutionary mechanisms link these two trajectories which makes them responsible for a variety of constitutional arrangements. 